\title{
Intoxication with new psychoactive substances in patients diagnosed at the Department of Clinical and Forensic Toxicology, Pomeranian Medical University in Szczecin in 2015-2018
}

\author{
Barbara Potocka-Banaśs ${ }^{1, A 凶}$, Urszula Semeniuk, B, Sławomir Majdanik ${ }^{2, C}$, Krzysztof Borowiak, D, \\ Tomasz Janus, ${ }^{1, \mathrm{E}}$ \\ 1 Pomeranian Medical University in Szczecin, Department of Clinical and Forensic Toxicology, Powstańców Wlkp. 72, 70-110 Szczecin, Poland \\ 2 Pomeranian Medical University in Szczecin, Department of Forensic Medicine, Powstańców Wlkp. 72, 70-110 Szczecin, Poland \\ A ORCID: 0000-0003-0259-2006; B ORCID: 0000-0003-0247-4202; C ORCID: 0000-0003-0472-1924; D ORCID: 0000-0002-2526-2686; E ORCID: 0000-0002-2363-2196 \\ $\triangle$ bpotocka@pum.edu.pl
}

\begin{abstract}
Introduction: Intoxication with new psychoactive substances (NPSs), colloquially known as designer drugs, has become a significant problem in the last several years.

The aim of the study was to conduct a statistical analysis of retrospective data from test records for the presence of NPSs in patients hospitalized in 2015-2018 in the West Pomeranian province.

Materials and methods: We analyzed 5,916 results of tests undertaken at the Department of Clinical and Forensic Toxicology at Pomeranian Medical University in Szczecin. Blood samples had been analyzed by liquid chromatography coupled with mass spectrometry (LC/MS) and Headspace gas chromatography (GC/Headspace).
\end{abstract}

Results: Our research was based on 5,916 diagnostic tests for poisoning with volatile and non-volatile organic compounds carried out in 2015-2018 at Pomeranian Medical University in Szczecin. Psychoactive substances used for non-medical purposes were detected in 1,465 patients. In the period under analysis 1,328 of these patients were poisoned with classic psychoactive substances, the poisonings caused by the intentional use NPS were recorded in 137 .

Conclusions: A retrospective analysis of the above-mentioned data for the period 2015-2018 revealed a gradual increase in the incidence of poisoning with psychoactive substances used for non-medical purposes.

Keywords: intoxication; new psychoactive substances; designer drugs; data analysis; diagnostic tests.

\section{INTRODUCTION}

Intoxication with new psychoactive substances (NPSs) has become a common and serious clinical, social and forensic problem in the last several years. These substances, colloquially known as designer drugs, are compounds that have been chemically altered from controlled substances and are usually sold online $[1,2]$. They are distributed in packages with labels that do not precisely describe their contents, and their names refer, e.g. to the characters of pop culture (Pink Panther), collectors' items (driver's charm), or items of everyday use (moisture absorber). The term "new psychoactive substances" suggests that these compounds produce only psychoactive effects, while in fact only some of them do so. Considering the chemical structure and mechanisms of action, NPSs are classified into 4 major groups [3]:

- $\quad$ psychostimulants ( $\beta$-cathinone derivatives, piperazine derivatives, 2,5-dimethoxyphenethylamine derivatives, called 2Cs),

- $\quad$ synthetic cannabinoids (indole derivatives, cyclohexylphenol derivatives, classic cannabinoids),

- hallucinogens (derivatives of tryptamine, phenylethylamine and arylcyclohexylamine),

- $\quad$ synthetic opioids.
The most popular and largest group are psychostimulants, which act on the central nervous system (CNS) and often produce effects comparable to those elicited by cocaine, amphetamine and MDMA (3,4-methylenedioxymethamphetamine), i.e. increased psychomotor activity, euphoria, anorexia, insomnia. Psychostimulants cause a broad spectrum of adverse effects. These include cardiovascular symptoms such as sinus tachycardia, palpitations, chest pain, hypertension, myocarditis, cardiac arrest; haematological problems such as disseminated intravascular coagulation, thrombocytopaenia, anaemia; cognitive dysfunction, e.g. confusion, chronic cognitive impairment, reduced mental performance; emotional problems such as irritability, aggression, panic attacks, anhedonia, depression, suicidal thoughts; neurological symptoms, e.g. insomnia, hyperthermia, mydriasis, visual disturbances, paraesthesia, bruxism, dyskinesia, headache and dizziness; perception disorders - paranoid delusions, auditory and visual hallucinations [4].

Synthetic cannabinoids are agonists of the CB1 and CB2 receptors. Despite the altered chemical structure, which is often entirely different from that of natural cannabinoids, they can produce effects up to 500 times more potent in the mechanism stimulating the CB1 receptor pathway (central), and the $\mathrm{CB} 2$ receptor pathway (peripheral), and elicit narcotic, 
empathogenic, intoxicating/psychotropic effects similar to those of $\Delta$-9-THC found in cannabis products i.e., marijuana and hashish. Information on the pharmacological properties and toxicity of synthetic cannabinomimetics is very limited, but clinical data imply a broad spectrum of toxic effects from cannabinol analogues. The most frequently reported adverse effects include disorders of the cardiovascular system, such as hypertension, tachycardia, arrhythmia, chest pain, shortness of breath, and myocardial infarction. Neurological symptoms are equally frequent: seizures, including tonic-clonic seizures, sleep disorders, headaches and dizziness. Abuse of these substances also leads to psychiatric disorders: panic and anxiety attacks, hallucinations, delusional psychosis, aggressive behaviour, and depression. Cognitive impairment has also been reported, including disorientation and disorders of shortterm memory [5].

Most hallucinogens activate the serotonin $5-\mathrm{HT}_{2}$ receptor, mainly the $5-\mathrm{HT}_{2} \mathrm{~A}$ subtype. Hallucinogens cause changes in consciousness, perceptual anomalies, and hallucinations. The psychedelic effects of hallucinogens largely depend on the personality traits and emotional state of the user, as well as the expectations and the circumstances. Toxic effects observed after the use of hallucinogens include increased heart rate, increased blood pressure, risk of serotonin syndrome, clonic seizures, insomnia, delirium, and rhabdomyolysis [6].

New designer opioids act on the $\mu$, $\partial$, and к opioid receptors, mainly in the CNS and less in the peripheral tissues. The activation of central opioid receptors produces an analgesic effect, relieves anxiety and panic attacks, causes mood changes, and lowers the seizure threshold. Toxic effects include constipation, dizziness, reduced blood pressure, seizures, liver damage, and respiratory depression leading to death [7].

The aim of the study was to conduct a statistical analysis of retrospective data from tests for the presence of NPSs in patients hospitalized in 2015-2018 in the West Pomeranian province. We analyzed 5,916 results of tests undertaken at the Department of Clinical and Forensic Toxicology, Pomeranian Medical University in Szczecin (DoCaFT PMU in Szczecin).

\section{MATERIALS AND METHODS}

The study presents a retrospective analysis of data from toxicology tests carried out at DoCaFT PMU in Szczecin in 2015-2018 and commissioned by 18 hospitals from the West Pomeranian province. Overall, we analyzed results and medical data from referrals for 5,916 cases, from which 1,465 patients tested positive for the presence of psychoactive substances used for nonmedicinal purposes. Blood samples were analyzed by liquid chromatography coupled with mass spectrometry (LC/MS) and Headspace gas chromatography (GC/Headspace). The number of NPSs detected in the tests was compared to the number of all psychoactive substances detected in poisoned patients.

\section{RESULTS}

In the period 2015-2018, psychoactive substances, both classic and designer drugs used for non-medical purposes, were detected in blood samples from 1,465 patients. The 1st group (classic substances) included: ethyl alcohol, amphetamine, methamphetamine, cocaine, tetrahydrocannabinol, MDMA, Ecstasy, and lysergic acid diethylamide (LSD). The 2nd group included NPSs, also known as designer drugs.

In the analysed period 1,328 patients were hospitalized because of intoxication with classic psychoactive substances, and 137 patients were diagnosed with poisoning caused by NPSs.

The study was based on blood samples collected from patients tested at DoCaFT PMU in Szczecin for the presence of psychoactive substances. The tests for the presence of psychoactive substances were positive in 314 patients $(21.4 \%)$ in 2015 , for 371 patients $(25.3 \%)$ in 2016 , for 382 patients $(26.1 \%)$ in 2017, and for 398 patients (27.2\%) in 2018 (Fig. 1).

The tests for the presence of NPSs were positive in 8 patients $(0.54 \%)$ in 2015,19 patients $(1.29 \%)$ in 2016,46 patients $(3.13 \%)$ in 2017, and 64 patients (4.36\%) in 2018 (Fig. 2).

Analysis of the data for 2015 showed that synthetic cannabinoid (1-pentyl-1H-indol-3-yl) (2,2,3,3-tetramethylcyclopropyl)

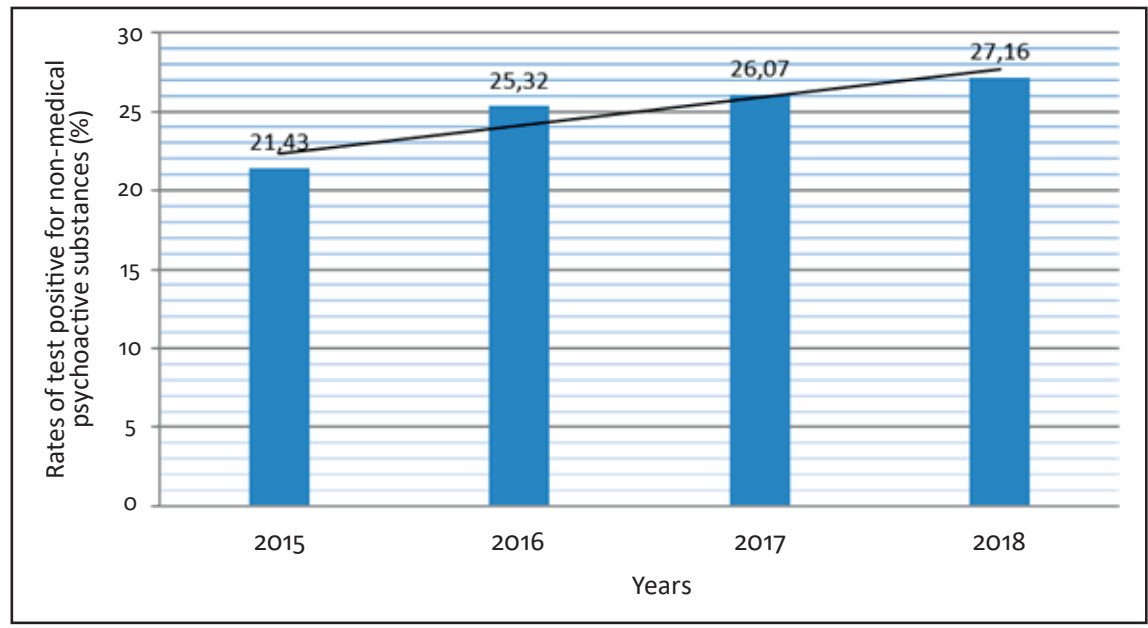

FIGURE 1. Share of positive tests for psychoactive substances used for non-medical purposes annually across the period 2015-2018 in the total sample of positive tests $(n=1465)$ 


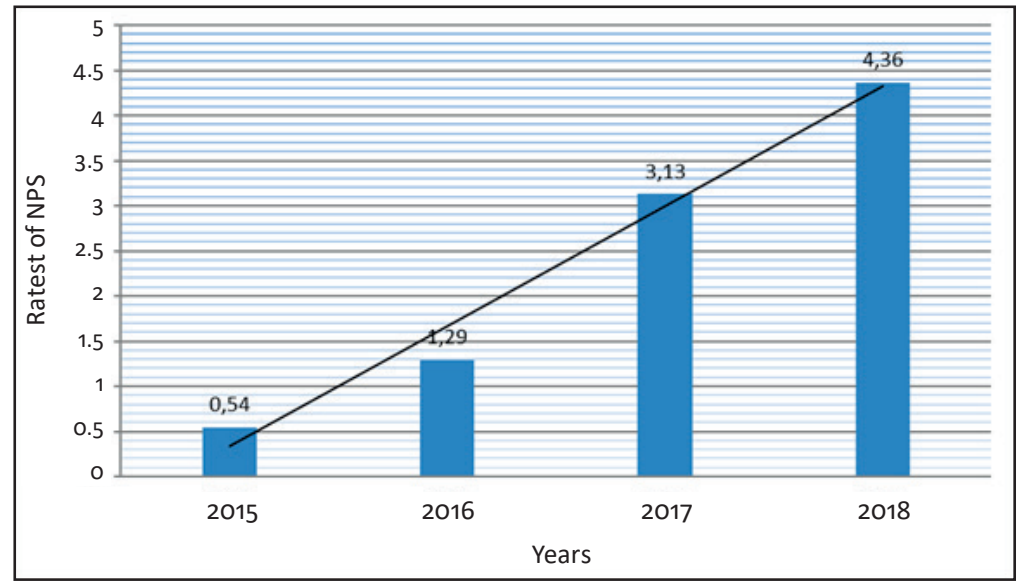

FIGURE 2. Positive tests for the presence of new psychoactive substances in all tests for psychoactive substances in $2015-2018$

methanone (UR-144) was the most frequently detected NPS, detected in 4 patients (1.27\%). Another substance, $\alpha$-pyrrolidinovalerophenone ( $\alpha$-PVP) from the group of psychostimulants, was detected in blood samples from 2 patients (0.63\%). Mephedrone, also known as 2-(methylamino)1-(4-methylphenyl)propan-1-one (4 MMC), a psychostimulant, was detected in 1 patient (0.31\%). Psychostimulant 3-2-(methylamino)-1-(3-methylphenyl)-1-propanone (3-mephedrone) was also detected in 1 patient (0.31\%) - Table 1.

TABLE 1. New psychoactive substances detected in the blood of patients in 2015

\begin{tabular}{lcc}
$\begin{array}{c}\text { New psychoactive } \\
\text { substance }\end{array}$ & Number of cases & $\begin{array}{c}\text { The incidence rate of } \\
\text { poisoning (\%) }\end{array}$ \\
\hline UR-144 & 4 & 1.27 \\
\hline a-PVP & 2 & 0.63 \\
\hline Mephedrone & 1 & 0.31 \\
\hline 3-mephedrone & 1 & 0.31 \\
\hline
\end{tabular}

Analysis of the data for 2016 showed that 1-(4-chlorophenyl)2-(methylamino)propan-1-one (4-CMC, clephedrone) from the group of psychostimulants was the most frequently detected NPS (5 patients; 1.34\%). The psychostimulant $\alpha$-PVP was detected in 4 patients $(1.07 \%)$. Psychostimulating 1-(4-chlorophenyl)-2-(ethylamino)propan-1-one (4-CEC, 4 -chloroethcathinone) was found in 3 patients $(0.80 \%)$. A synthetic cannabinoid, methyl (2S)-2-[[1-(cyclohexylmethyl) indole-3-carbonyl]amino]-3,3-dimethylbutanoate (MDMB-CHMICA), was detected in $2(0.53 \%)$ patients. A synthetic cannabinoid, methyl (2S)-2-[[1-[(4-fluorophenyl)methyl] indazole-3-carbonyl]amino]-3-methylbutanoate (FUB-AMB), psychostimulating 2-(methylamino)-1-(4-methylphenyl)1-butanone (4-methylbuphedrone), psychostimulating 1-(2H-1,3-benzodioxol-5-yl)-2-(ethylamino)pentan-1-one (N-ethylpentylone), psychostimulating methyl (4-fluorophenyl) (piperidin-2-yl)acetate (4F-MPH), and a synthetic cannabinoid, $\mathrm{N}$-(1-amino-3,3-dimethyl-1-oxobutan-2-yl)-1-[(4-fluorophenyl) methyl]indazole-carboxamide (ADB-FUBINACA), were detected in single patients $(0.26 \%$ each) - Table 2.

Analysis of the data for 2017 revealed that $\alpha$-PVP was the most frequently detected NPS, identified in 11 patients (2.87\%). Other frequently detected substances were psychostimulants: 4-CMC (7 patients; $1.83 \%$ ) and 4-CE (7 patients; $1.83 \%)$. A synthetic cannabinoid, MDMB-CHMICA, was detected in 6 patients (1.57\%). Another synthetic cannabinoid, (S)-methyl 2-(1-(5-fluoropentyl)-1H-indazole-3-carboxamido)-3-methylbutanoate $(5 \mathrm{~F}-\mathrm{AMB})$, was found in 2 patients $(0.52 \%)$. The synthetic opioid, 3,4-dichloro-N-(2-(dimethylamino)cyclohexyl)$\mathrm{N}$-methylbenzamide (U-47700), was detected for the 1st time in 2 patients (0.52\%). Other substances, i.e. N-ethylpentylone, psychostimulating 2-(Ethylamino)-1-phenyl-1-pentanone (NEP, N-ethylnorpentedrone), a synthetic cannabinoid N-(1-adamantyl)-1-(5-fluoropentyl)indazole-3-carboxamide (5-F-AKB-48), hallucinogenic 1-[1-(3-methoxyphenyl)cyclohexyl] piperidine (4-MeO-PCP), psychostimulating 1-(3-chlorophenyl) piperazine (m-CPP), psychostimulating 1-(4-fluorophenyl)propan-2-amine (4-FA), hallucinogenic 3-[2-[ethyl(methyl)amino] ethyl]-1H-indol-4-ol (4-HO-Met), psychostimulating 4-F-PHP,

TABLE 2. New psychoactive substances detected in the blood of patients in 2016

\begin{tabular}{lcc}
$\begin{array}{c}\text { New psychoactive } \\
\text { substance }\end{array}$ & Number of cases & $\begin{array}{c}\text { The incidence rate of } \\
\text { poisoning (\%) }\end{array}$ \\
\hline Clephedrone (4-CMC) & 5 & 1.34 \\
\hline$\alpha-P V P$ & 4 & 1.07 \\
\hline 4-CEC & 3 & 0.80 \\
\hline MDMB-CHMICA & 2 & 0.53 \\
\hline FUB-AMB & 1 & 0.26 \\
\hline 4-methylbuphedrone & 1 & 0.26 \\
\hline N-ethylpentylone & 1 & 0.26 \\
\hline 4F-MPH & 1 & 0.26 \\
\hline ADB-FUBINACA & 1 & 0.26 \\
\hline
\end{tabular}


synthetic cannabinoid MDMB-CHMICA, psychostimulating mephedrone, hallucinogenic 3-[2-[methyl(propan-2-yl)amino] ethyl]-1H-indol-4-ol (4-HO-MiPT), were each detected in individual patients $(0.26 \%$ each) - Table 3 .

Analysis of data for 2018 revealed another significant increase in the number of cases of acute intoxication with NPSs. The most frequently detected NPS was psychostimulating clephedrone, detected in 29 (7.28\%) patients. The 1st case of psychostimulating 2-(ethylamino)-1-phenylhexan-1-one (HEX-EN, $\mathrm{N}$-ethylhexedrone) was detected in 12 patients (3.01\%). Another psychostimulant, 1-(4-Methylphenyl)-2-methylamino-pentan-1-one (4-MDP), was detected in 4 patients (1.0\%). Psychostimulating 1-(1,3-benzodioxol-5-yl)-2-pyrrolidin-1-ylhexan1-one (MDPHP) was detected in 3 patients (0.75\%). Synthetic cannabinoid, methylN-\{[1-(cyclohexylmethyl)-1H-indol-3-yl] carbonyl\}-L-valinate (MMB-CHMICA), was detected in blood samples from 2 patients (0.50\%). Another synthetic cannabinoid, (RS)-1-(4-Methylphenyl)-2-(1-pyrrolidinyl)-1-hexanone (MPHP), was found in blood from 2 patients (0.50\%). Other psychostimulants were also detected: $4 \mathrm{~F}-\mathrm{MPH}$ in 2 patients (0.50\%), and N-ethylpentylone in 2 patients $(0.50 \%)$. There were also single cases of poisoning with psychostimulating 2-(methylamino)-1-phenylpentan-1-one (pentedrone), a synthetic cannabinoid, methyl 2-[[1-(5-fluoropentyl)indole-3-carbonyl]

TABLE 3. New psychoactive substances detected in the blood of patients in 2017

\begin{tabular}{lcc}
$\begin{array}{c}\text { New psychoactive } \\
\text { substance }\end{array}$ & Number of cases & $\begin{array}{c}\text { The incidence rate of } \\
\text { poisoning (\%) }\end{array}$ \\
\hline a-PVP & 11 & 2.87 \\
\hline Clephedrone (4-CMC) & 7 & 1.83 \\
\hline 4-CEC & 7 & 1.83 \\
\hline AMB-CHMICA & 6 & 1.57 \\
\hline 5F-AMB & 2 & 0.52 \\
\hline U-47700 & 2 & 0.52 \\
\hline N-ethylpentylone & 1 & 0.26 \\
\hline N-ethylpentedrone & 1 & 0.26 \\
\hline 5F-AKB48 & 1 & 0.26 \\
\hline 4-MeO-PCP & 1 & 0.26 \\
\hline mCPP & 1 & 0.26 \\
\hline 4FA & 1 & 0.26 \\
\hline 4-HO-met & 1 & 0.26 \\
\hline 4F-PHP & 1 & 0.26 \\
\hline MDMB-CHMICA & 1 & 0.26 \\
\hline Mephedrone & 1 & 0.26 \\
\hline 4HO-MiPT & 1 & 0.26 \\
\hline
\end{tabular}

amino]-3,3-dimethyl-butanoate (5F-MDMB-PICA), psychostimulating (RS)-1-(4-Fluorophenyl)-N-methylpropan-2-amine (4-FMA), psychostimulating (RS)-2-ethylamino-1-phenyl-propan1-one (ethcathinone), psychostimulating N-ethylpentylone, psychostimulating propan-2-yl 2-phenyl-2-(piperidin-2-yl) acetate (isopropylphenidate), hallucinogenic 4-HO-Met, and a synthetic cannabinoid, 5 F-AMB (each accounted for $0.26 \%$ of all positive tests) - Table 4 .

TABLE 4. New psychoactive substances detected in the blood of patients in 2018

\begin{tabular}{|c|c|c|}
\hline $\begin{array}{c}\text { New psychoactive } \\
\text { substance }\end{array}$ & Number of cases & $\begin{array}{c}\text { The incidence rate of } \\
\text { poisoning (\%) }\end{array}$ \\
\hline Clephedrone (4-CMC) & 26 & 7.28 \\
\hline $\begin{array}{l}\text { N-ethylhexedrone } \\
\text { (HEX-EN) }\end{array}$ & 12 & 3.01 \\
\hline 4-MDP & 4 & 1.00 \\
\hline MDPHP & 3 & 0.75 \\
\hline 4-CMC & 3 & 0.75 \\
\hline MMB-CHMICA & 2 & 0.50 \\
\hline LSD & 2 & 0.50 \\
\hline MPHP & 2 & 0.50 \\
\hline 4F-MPH & 2 & 0.50 \\
\hline N-ethylpentylone & 2 & 0.50 \\
\hline Pentedrone & 1 & 0.25 \\
\hline 5F-MDMB-PICA & 1 & 0.25 \\
\hline 4-FMA & 1 & 0.25 \\
\hline ethcathinone & 1 & 0.25 \\
\hline N-ethylnorpentedrone & 1 & 0.25 \\
\hline isopropylphenidate & 1 & 0.25 \\
\hline 4-HO-Met & 1 & 0.25 \\
\hline 5F-AMB & 1 & 0.25 \\
\hline
\end{tabular}

\section{DISCUSSION AND CONCLUSION}

Between 2015-2018 the DoCaFT PMU in Szczecin carried out 5,916 diagnostic tests for poisoning with volatile and non-volatile organic compounds. Psychoactive substances used for non-medical purposes were detected in 1,465 patients. In the analyzed period 1,328 of these patients were poisoned with classic psychoactive substances, and in 137 of these tests, poisoning was caused by the intentional use of NPSs.

Retrospective analysis of the data for the period 2015-2018 (Fig. 1 and 2) revealed a gradual increase in the incidence of poisonings with psychoactive substances used for non-medical purposes. A similar increase was found in the number of 
poisonings with NPSs. This implies a growing popularity of these drugs among patients. Importantly, tests carried out in subsequent years detected NPSs in patients' blood: 4 drugs in 2015, 9 in 2016, 17 in 2017, and 18 in 2018. Apparently, the major reason for the emergence of NPSs is changes in Polish legislation and faster inclusion of NPSs in regularly updated annexes to the Act of 29 July 2005 on counteracting drug addiction. These results, among other things, in criminal sanctions for the possession of substances listed in the Act on Counteracting Drug Addiction. To avoid criminal responsibility, designer drug manufacturers modify the chemical structure of the listed designer drugs in order to put on the market derivatives that are not yet monitored. Due to these modifications, even minor ones, the emerging substances may produce dramatically different and unpredictable effects, both short-term (acute) and long-term (chronic). Knowledge of the clinical symptoms of poisoning, and toxic and fatal doses of NPSs is very limited because of the dynamic changes in NPSs appearing on the market.

The European Monitoring Centre for Drugs and Drug Addiction (EMCDDA) reported that over 670 NPSs were monitored in Europe by the end of 2017, and 51 of them were identified for the 1st time [8].

The rapid emergence of modified NPSs creates diagnostic problems and also clinical difficulties in the treatment and medical care of poisoned patients. Most drug users are unaware of the substances contained in the powders (salts, herbs) because these products have multiple ingredients and lack label information about the chemical composition. A common problem, particularly concerning the production of synthetic cannabinoids, is the non-uniform distribution of substances in "herbal smoking blends", and thus different packages of the same products containing structurally identical substances may have different concentrations, which is not precisely indicated on the label.

Identification of NPSs is problematic not only because of their complex, often unknown chemical structure, but also the low availability of methods and analytical equipment for their detection. This type of assay requires advanced analytical techniques such as LC/MS, and also highly qualified personnel who can conduct analyses for NPSs correctly and efficiently.

The EMCDDA report for 2018 revealed that synthetic cannabinoids and psychostimulant synthetic cathinones were the most frequently seized NPSs [8]. This was also supported by data from a Turkish report in 2016-2017, which indicated that synthetic cannabinoids were the most popular group of drugs detected in poisoning cases [9].

Analysis of the data from DoCaFT PMU in Szczecin for the period 2015-2018 revealed that psychostimulant NPSs were the most frequently detected (78.8\%), with 4-CMC the most frequently found. The popularity of 4-CMC may be attributed to its effects, which include mood lift, and feelings of relaxation and laziness rather than euphoria. Synthetic cathinones from the group of psychostimulant drugs are, according to the literature, among the most popular NPSs used as an alternative to classic drugs such as cocaine, ecstasy and amphetamines [10].
Synthetic cannabinoids were detected in $17.5 \%$ of positive tests for NPSs and were the 2nd most frequently used designer drug detected at DoCaFT PMU in Szczecin. Only 2.2\% of patients tested positive for hallucinogens. Analysis revealed that opioids were the least popular group of NPSs among the diagnosed patients, with only 1 patient (1.5\%) testing positive for the opioid substance (U-477).

This trend is also confirmed by data presented in the EMCDDA report, which shows that opioid derivatives represent a small percentage of NPSs on the European market, yet they cause serious harm due to their very high potency [8]. Despite statistics indicating that synthetic opioids accounted only for $2 \%$ of all seized drugs, researchers point to the alarmingly high rate at which this group of substances reaches the market, and this particularly concerns synthetic fentanyl derivatives in the last 3 years. Easier access to fentanyl analogs is associated with a high risk of drug overdose, risk of acute intoxications and fatalities $[11,12]$.

Statistical analysis of data for the period 2015-2018 showed a steady year-on-year increase in the incidence of poisonings with NPSs, as well as an increase in the range of detected designer drugs.

\section{REFERENCES}

1. Michael FW, Hopper JA, Gunderson EW. Designer drugs 2015: assessment and management. Addict Sci Clin Pract 2015;10(1):8. doi: 10.1186/ s13722-015-0024-7.

2. Korf D, Benschop A, Werse B, Kamphausen G, Felvinczi K, Dąbrowska $\mathrm{K}$, et al. How and where to find NPS users: a comparison of methods in a cross-national survey among three groups of current users of new psychoactive substances in Europe. Int J Ment Health Addict 2019;17:1-18. doi: 10.1007/s11469-019-0052-8.

3. Zawilska JB, Wojcieszak J, Andrzejczak D. „Dopalacze” i leki OTC - nowi gracze na scenie związków psychoaktywnych. Warszawa: Biuro Upowszechniania i Promocji Nauki PAN; 2016. p. 33-107.

4. Lappin JM, Sara GE. Psychostimulant use and the brain. Addiction 2019;114(11):2065-77. doi: 10.1111/add.14708.

5. Mills B, Yepes A, Nugent K. Synthetic Cannabinoids. Am J Med Sci 2015;350(1):59-62.

6. Halberstadt AL. Hallucinogenic drugs: a new study answers old questions about LSD. Curr Biol 2017;27(4):R156-R158.

7. Armenian P, Vo KT, Barr-Walker J, Lynch KL. Fentanyl, fentanyl analogs and novel synthetic opioids: a comprehensive review. Neuropharmacology 2018;134(Pt A):121-32.

8. European Monitoring Centre for Drugs and Drug Addiction. European Drug Report 2018: Trends and Developments. Luxembourg: EU Publications; 2018.

9. Göl E, Çok I. New psychoactive substances in Turkey: narcotics cases assessed by the council of forensic medicine between 2016 and 2017 in Ankara, Turkey. Forensic Sci Int 2019;294:113-23. doi: 10.1016/j.forsciint.2018.11.003.

10. Zaami S, Giorgetti R, Pichini S, Pantano F, Marinelli E, Busardò FP. Synthetic cathinones related fatalities: an update. Eur Rev Med Pharmacol Sci 2018;22(1):268-74.

11. Pichini S, Pacifici R, Marinelli E, Busardò FP. European drug users at risk from illicit fentanyls mix. Front Pharmacol 2017;8:785.

12. Pichini S, Solimini R, Berretta P, Pacifici R, Busardò FP. Acute intoxications and fatalities from illicit fentanyl and analogues: An update. Ther Drug Monit 2018;40(1):38-51. doi: 10.1097/FTD.0000000000000465. 